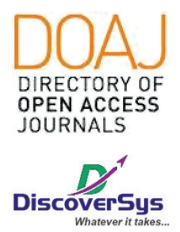

Published by DiscoverSys

\section{Hubungan insomnia dengan depresi pada lanjut usia di Sesetan Kecamatan Denpasar Selatan Tahun 2017}

CrossMark

\author{
Luh Putu Mettary Yasoda Gera, ${ }^{1 *}$ Anak Ayu Sri Wahyuni, ${ }^{2}$ IGA Indah Ardani ${ }^{2}$
}

\section{ABSTRACT}

Introduction: Insomnia is difficulty falling or maintaining sleep that often experienced by general population. Insomnia mostly experienced by elderly woman, people with low education and low economy and in people who have chronic disease. Insomnia is risk factor from psychiatric disorder especially depression. Insomnia increase the risk in depression development. Depression is disorder on personal, interpersonal and social that affecting general population. The purpose of this study is to know the relationship between insomnia and depression in elderly. Method: The type of this study is analytical observational (Crosssectional) study with amount of sample 32 respondents that conducted in Banjar Gaduh and Banjar Tengah in Sesetan, South Denpasar District in elderly in 2017. This study is using the primary data obtained through questionnaire and interview (GDS and ISI) and analyzed through SPSS 21.0.

Result: This study found that from 32 respondents experienced insomnia (50\%), not experienced Insomnia (50\%), experienced depression (28.1\%) and no experience depression (71.9\%) and relationship insomnia with depression on eldery obtained value $p<0.05$. The $R$-square value indicates value of 0.673 which means that role variable independent in explain variable dependent only of $67.3 \%$, could be concluded that still there are $24.6 \%$ other variables outside the research variables that affect insomnia.

Conclusion: There were a significant relationships between depression and insomnia.
1Program Studi Pendidikan Dokter Fakultas Kedokteran Universitas Udayana

${ }^{2}$ Bagian/SMF Psikiatri, Fakultas Kedokteran Universitas UdayanaRSUP Sanglah Denpasar

${ }^{*}$ Correspondence to:

Luh Putu Mettary Yasoda Gera, Program Studi Pendidikan Dokter Fakultas Kedokteran Universitas Udayana myasodagera27@gmail.com

Diterima: 29-03-2018

Disetujui: 02-05-2018

Diterbitkan: 01-08-2019
Keywords: depression, insomnia, eldery.

Cite This Article: Gera, L.P.M.Y. Wahyuni, A.A.S., Ardani, I.G.A.I. 2019. Hubungan insomnia dengan depresi pada lanjut usia di Sesetan Kecamatan Denpasar Selatan Tahun 2017. Intisari Sains Medis 10(2): 268-272. D01: 10.15562/ism.v10i2.188
Latar Belakang: Insomnia adalah kesulitan memulai atau mempertahankan tidur yang sering dialami pada populasi umum. Insomnisa kebanyakan dialami oleh perempuan dengan lanjut usia, orang dengan pendidikan rendah dan ekonomi rendah serta pada orang yang mengalami penyakit kronis. Insomnia merupakan faktor resiko dari gangguan psikiatri terutama depresi. Insomnia meningkatkan resiko dalam perkembangan depresi. Depresi merupakan gangguan pada pribadi, interpersonal dan sosial yang mempengaruhi populasi umum. Tujuan penelitian ini untuk mengetahui hubungan insomnia dengan depresi pada lanjut usia.

Metode: Jenis penelitian ini adalah penelitian analitik observasional (Cross-sectional) dengan jumlah sampel 32 responden yang dilakukan di Banjar Gaduh dan Banjar Tengah di Sesetan Kecamatan Denpasar Selatan pada Lanjut Usia tahun 2017. Penelitian ini menggunakan data primer yang diperoleh melalui koesioner wawancara (GDS dan ISI) dan dianalisis melalui SPSS 21.0.

Hasil: Hasil penelitian bahwa dari 32 responden didapatkan subjek mengalami insomnia (50\%), tidak mengalami Insomnia (50\%), mengalami depresi $(28,1 \%)$ dan tidak mengalami depresi $(71,9 \%)$ dan hubungan insomnia dengan depresi pada lanjut usia diperoleh nilai $P<0,05$. Nilai R-square menunjukkan nilai 0,673 yang berarti bahwa peranan variabel independen dalam menjelaskan variabel dependen hanyalah sebesar $67,3 \%$, hal tersebut dapat disimpulkan bahwa masih terdapat $24,6 \%$ variabel lain diluar dari variabel yang dilakukan penelitian ini yang mempengaruhi insomnia.

Simpulan: Penelitian ini terdapat hubungan yang bermakna antara depresi dan insomnia.

Kata kunci: depresi, insomnia, lanjut usia.

Cite Pasal Ini: Gera, L.P.M.Y. Wahyuni, A.A.S., Ardani, I.G.A.I. 2019. Hubungan insomnia dengan depresi pada lanjut usia di Sesetan Kecamatan Denpasar Selatan Tahun 2017. Intisari Sains Medis 10(2): 268-272. D0I: 10.15562/ism.v10i2.188

\title{
PENDAHULUAN
}

Gangguan tidur merupakan gangguan pola tidur yang dikaitkan dengan gangguan pada kondisi mental dan kesehatan. ${ }^{1}$ Gangguan tidur berdasarkan DSM - 5 (Diagnostic and statistical manual of mental disorders) mengelompokkan gangguan tidur berdasarkan kriteria diagnosis 
klinis dan perkiraan etiologi yang terdiri atas gangguan insomnia, hipersomnolense, narcolepsi, sleep apne, gangguan tidur terkait irama siskardian, parasomnia, gangguan tidur arousal, gangguan teror tidur, gangguan perilaku tidur, restless legs syndrome, dan gangguan tidur karena obat. ${ }^{2}$ Gangguan tidur merupakan suatu masalah yang sering muncul pada populasidiberbagainegara. Berdasarkan hasilsurveiCDC(CentersforDiseaseControland Prevention) diperkirakan 50 - 70 juta orang Amerika mengalami gangguan tidur. Semakin bertambahnya usia seseorang kemungkinan mengalami gangguan tidur $5 \%$ pada usia 30 - 50 tahun dan $30 \%$ pada usia diatas 50 tahun. Di China 0.18 juta lanjut usia yang lebih dari 60 tahun atau sekitar $13.3 \%$. Dari populasi tersebut prevalensi gangguan tidur pada lanjut usia antara 6\% sampai $40 \%{ }^{1}$

Gangguan tidur pada lanjut usia merupakan suatu proses normal yang dikaitkan dengan proses penuaan. Gangguan tidur dikaitkan dengan hal negatif dalam morbiditi dan mortaliti pada populasi lanjut usia. Berdasarkan hasil studi sebagian besar jumlah lanjut usia yang mengalami gangguan tidur dikaitkan dengan tempat tinggal yang buruk, kualitas hidup, gangguan psikiatri dan perubahan irama siskardian. ${ }^{3}$ Insomnia adalah kesulitan memulai atau mempertahankan tidur. Gangguan ini merupakan keluhan yang paling sering ditemui dan bersifat sementara atau menetap. ${ }^{2}$

Insomnia merupakan keluhan yang sering dialami padapopulasiumum. Insomnisakebanyakan dialamioleh perempuandengan lanjut usia, orang dengan pendidikan rendah dan ekonomi rendah serta pada orang yang mengalamipenyakitkroni. ${ }^{4}$ Sekitar 50\% dari populasi lanjut usia mengalami insomnia. ${ }^{5}$ Insomnia merupakan faktor resiko dari gangguan psikiatri terutama depresi. Insomnia meningkatkan resiko dalam perkembangan depresi. ${ }^{5,15}$

Depresi merupakan gangguan pada pribadi, interpersonal dan sosial yang mempengaruhi $15 \%$ dari populasi umum. Perempuan dua kali lebih besar mengalamidepresidan gejalapadaumumnyameningkan berdasarkan usia. Depresi terkaittidak hanyamiskin, kualitashidup, peningkatan komorbiditas, menurunnya harapan hidup, hilangnya otonomi dan resiko bunuh diri disertai penyakit kronis. ${ }^{7}$ Insomnia merupakan faktor resiko dari gangguan psikiatri terutama depresi. Insomnia meningkatkan resiko dalam perkembangan depresi. Insomnia dan depresi memiliki hubungan dua arah. ${ }^{6}$ Insomnia terdapat dalam daftar DSM - 5 (Diagnostic and statistical manual of mental disorders) pada diagnosis depresi sehingga membuktikan bahwa terdapat hubungan dekat antara insomnia dan depresi. Hal ini menarik perhatian dari peneliti untuk meneliti tentang hubungan insomnia dengan depresi pada lanjut usia di Denpasar pada tahun 2017.

\section{METODE}

Penelitian ini menggunakan rangangan potong lintang analitik oleg karena seluruh variabel diukur dalam satu periode yang sama. Subjek penelitian ini adalah perkumpulan lanjut usia (60 tahun) di Kecamatan Sesetan Denpasar Selatan, penelitian ini dilakukan pada bulan Agustus-September 2017. Subjek penelitian ini dicari melalui metode total sampling yang merekrut seluruh lansia yang ada dalam perkumpulan tersebut, kemudian lansia dilakukan pengkajian depresi melalui kuesioner geriatri depression scale (GDS) dan insomnia severity index. Analisis ditujukan untuk mengetahui hubungan antara insomnia dan depresi melalui metode analysis resiko odds ratio dan analysis regresi logistic multinominal untuk mengetahui variabel yang paling berperan terhadap insomnia pada lanjut usia.

\section{HASIL}

Pada penelitian ini digunakan 32 subjek penelitian, kemudian akan dipaparkan mengenai karakteristik subjek, serta hubungan antara insomnia dan depresi pada lanjut usia yang menjadi subjek penelitian. Karakteristik subjek penelitian ini meliputi usia, jenis kelamin, status perkawinan, pekerjaan, tingkat pendidikan, status depresi, dan status insomnia dapat dilihat pada tabel 1 .

Berdasarkan tabel 1 diatas dapat diketahui bahwa rerata usia pada subjek adalah 68 tahun, kemudian subjek dengan rerata usia 60-70 tahun cenderung lebih banyak yaitu dengan proporsi $68.8 \%$. Berdasarkan jenis kelamin ditemukan perempuan cenderung lebih banyak dibandingkan dengan jenis kelamin lakilaki yaitu dengan proporsi $68.8 \%$. Berdasarkan tingkat pendidikan, tingkat pendidikan rendah cenderung lebih banyak dibandingkan dengan tingkat pendidikan tinggi yaitu dengan proporsi 59.4\%. Berdasarkan status perkawinan, status janda/duda cenderung lebih banyak dibandingkan dengan status menikah yaitu dengan proporsi $31.2 \%$. Berdasarkan pekerjaan, kelompok subjek yang bekerja jauh lebih banyak dibandingkan dengan tidak bekerja yaitu dengan proporsi $68.8 \%$, proporsi insomnia pada subjek penelitian adalah $50 \%$, sedangkan proporsi depresi pada subjek penelitian adalah $28.1 \%$. analisis resiko melalui estimasi odd ratio terkait dengan hubungan insomnia dan depresi dapat dilihat pada tabel 2.

Berdasarkan tabel 2 diatas dapat diketahui bahwa pada kelompok subjek yang mengalami 
Tabel 1 Karakteristik Subjek

\begin{tabular}{|c|c|c|}
\hline Karakteristik & Jumlah (n = 32) & Persentase (\%) \\
\hline Usia (Mean \pm SD) & $68 \pm 6.3$ & $100 \%$ \\
\hline $60-70$ tahun & 22 & $68,8 \%$ \\
\hline $71-80$ tahun & 10 & $31,2 \%$ \\
\hline \multicolumn{3}{|l|}{ Jenis Kelamin } \\
\hline Laki-laki & 10 & $31,2 \%$ \\
\hline Perempuan & 22 & $68,8 \%$ \\
\hline \multicolumn{3}{|l|}{ Tingkat Pendidikan } \\
\hline Pendidikan Tinggi & 13 & $40,6 \%$ \\
\hline Pendidikan Rendah & 19 & $59,4 \%$ \\
\hline \multicolumn{3}{|l|}{ Status Perkawinan } \\
\hline Menikah & 10 & $31,2 \%$ \\
\hline Janda/Duda & 22 & $68,8 \%$ \\
\hline \multicolumn{3}{|l|}{ Pekerjaan } \\
\hline Bekerja & 22 & $68,8 \%$ \\
\hline Tidak Bekerja & 10 & $31,2 \%$ \\
\hline \multicolumn{3}{|l|}{ Status Depresi } \\
\hline Depresi & 9 & $28,1 \%$ \\
\hline Tidak Depresi & 21 & $71,9 \%$ \\
\hline \multicolumn{3}{|l|}{ Status Insomnia } \\
\hline Insomnia & 16 & $50 \%$ \\
\hline Tidak Insomnia & 16 & $50 \%$ \\
\hline
\end{tabular}

Tabel 2 Analisis resiko insomnia dan depresi

\begin{tabular}{lllllll}
\hline & & \multicolumn{2}{c}{ Status Insomnia } & & & \\
\cline { 3 - 4 } Variabel & & Insomnia & $\begin{array}{c}\text { Tidak } \\
\text { Insomnia }\end{array}$ & OR & IK 95\% & Nilai p \\
\hline \multirow{2}{*}{ Status } & Depresi & $7(43.8 \%)$ & $2(12.5 \%)$ & & & \\
Depresi & $\begin{array}{l}\text { Tidak } \\
\text { Depresi }\end{array}$ & $9(56.3 \%)$ & $14(87.5 \%)$ & & & \\
& & & & & & \\
\end{tabular}

depresi cenderung untuk mengalami insomnia dibandingkan dengan tidak insomnia yaitu dengan proporsi $43.8 \%$, sedangkan pada kelompok yang tidak mengalami depresi cenderung untuk tidak mengalami insomnia dibandingkan dengan insomnia yaitu dengan proporsi $87.5 \%$.

Melalui analisis odd ratio didapatkan nilai $\mathrm{OR}=$ 5.44 yang berarti peluang untuk menemukan orang yan depresi adalah empat kali lebih besar pada kelompok yang mengalami insomnia dibandingkan dengan tidak insomnia, dan dapat disimpulkan bahwa depresi merupakan faktor resiko insomnia. Nilai $\mathrm{p}=0.049(\mathrm{p}<0.05)$ sehingga dapat disimpulkan bahwa terdapat hubungan yang bermakna antara depresi dan insomnia.

Analisis regresi logistik multinominal bertujuan untuk melakukan analisis secara bersamaan terkait dengan seluruh variabel independen terkait hubungannya dengan variabel dependen (insomnia) untuk menilai peranan dari masing-masing variabel secara keseluruhan, serta melakukan kontrol terhadap karakteristik yang bukan merupakan faktor resiko sehingga didapatkan suatu odd ratio yang telah disesuaikan (Adjusted Odd Ratio) yang dapat dilihat pada tabel 3.

Berdasarkan tabel 3 diatas setelah dilakukan analisis secara bersamaan terhadap seluruh variabel independen yang ada serta melakukan kontrol pada karakteristik subjek, tetap ditemukan hasil yang serupa bahwa depresi merupakan faktor resiko insomnia. Melalui hasil regresi logistic ditemukan nilai adjusted odd ratio untuk depresi adalah 27.482 (IK 95\% = 1.078-700.664) sehingga dapat disimpulkan bahwa peluang untuk menemukan orang yang depresi 27 kali lebih besar pada kelompok orang yang mengalami insomnia dibandingkan dengan tidak insomnia dan depresi merupakan faktor resiko insomnia. Nilai $p$ menunjukkan nilai $0.045(\mathrm{p}<0.005)$ sehingga terdapat hubungan yang bermakna antara depresi dan insomnia.

Berdasarkan status perkawinan, status janda/ duda memiliki nilai adjusted odd ratio 4.076 (IK $95 \%=0.286-59.016)$ sehingga dapat disimpulkan bahwa peluang untuk menemukan orang dengan status janda/duda 3mpat kali lebih besar pada kelompok orang yang mengalami insomnia dibandingkan dengan tidak insomnia dan janda/ duda merupakan faktor resiko dari insomnia. Nilai p menunjukkan nilai $0.300(p>0.05)$ sehingga tidak terdapat hubungan yang bermakna antara status perkawinan dan insomnia. (tabel 3)

Berdasarkan status pekerjaan, keadaan tidak bekerja memiliki nilai adjusted odd ratio 1.935 $(\mathrm{IK} 95 \%=0.158-24.278)$ sehingga dapat disimpulkan bahwa peluang untuk menemukan orang yang tidak bekerja 1.9 kali lebih besar pada kelompok yang mengalami insomnia dibandingkan dengan tidak insomnia dan tidak bekerja merupakan faktor resiko insomnia. Nilai p menunjukkan nilai 0.609 ( $>0.05$ ) sehingga tidak terdapat hubungan yang bermakna antara status peekerjaan dan insomnia. (tabel 3)

Berdasarkan tingkat pendidikan, keadaan pendidikan rendah memiliki nilai adjusted odd ratio $37.391(\mathrm{IK} 95 \%=1.770-789.960)$ sehingga dapat disimpulkan bahwa peluang untuk menemukan orang dengan tingkat pendidikan renda $37 \mathrm{kali}$ lebih besar pada kelompok yang mengalami insomnia dibandingkan dengan tidak insomnia dan tingkat pendidikan rendah merupakan faktor resiko insomnia. Nilai p menunjukkan nilai $0.02(\mathrm{p}<0.05)$ sehingga terdapat hubungan yang bermakna antara tingkat pendidikan dan insomnia. (tabel 3)

Variabel lain seperti jenis kelamin dan usia bukan merupakan faktor resiko dari insomnia, dan 
Tabel 3 Analisis multivariat regresi logistik pada karakteristik subjek dan depresi terhadap insomnia

\begin{tabular}{|c|c|c|c|c|}
\hline \multirow[b]{2}{*}{ Variabel } & \multirow[b]{2}{*}{ Nilai p } & \multirow[b]{2}{*}{ Adjusted OR } & \multicolumn{2}{|c|}{ IK 95\% OR } \\
\hline & & & Bawah & Atas \\
\hline \multicolumn{5}{|c|}{ Kelompok Umur $(n=32)$} \\
\hline $60-70$ (reff) & & 1 (reff) & & \\
\hline 71-70 Tahun & 0.143 & 0.155 & 0.003 & 2.527 \\
\hline \multicolumn{5}{|c|}{ Jenis Kelamin $(\mathrm{n}=32)$} \\
\hline Laki-Laki (reff) & & 1 (reff) & & \\
\hline Perempuan & 0,123 & 0.106 & 0.006 & 1.838 \\
\hline \multicolumn{5}{|c|}{ Status Pekerjaan $(n=32)$} \\
\hline Bekerja (reff) & & 1 (reff) & & \\
\hline Tidak Bekerja & 0.609 & 1.935 & 0.154 & 24.278 \\
\hline \multicolumn{5}{|c|}{ Status Pernikahan $(n=32)$} \\
\hline Menikah (reff) & & 1 (reff) & & \\
\hline Janda/Duda & 0.300 & 4.076 & 0.286 & 58.016 \\
\hline \multicolumn{5}{|c|}{ Tingkat Pendidikan $(\mathrm{n}=32)$} \\
\hline Tinggi (reff) & & 1 (reff) & & \\
\hline Rendah & $002^{*}$ & 37.391 & 1.770 & 789.960 \\
\hline \multicolumn{5}{|c|}{ Status Depresi $(n=32)$} \\
\hline Tidak Depresi & & 1 (reff) & & \\
\hline Depresi & $0.045^{\star}$ & 27.482 & 1.078 & 700.664 \\
\hline
\end{tabular}

tidak terdapat hubungan antara jenis kelamin, usia terhadap insomnia. Nilai R-square menunjukkan nilai 0.673 yang berarti bahwa peranan variabel independen dalam menjelaskan variabel dependen hanyalah sebesar $67.3 \%$, hal tersebut dapat disimpulkan bahwa masih terdapat $24.6 \%$ variabel lain diluar dari variabel yang dilakukan penelitian ini yang mempengaruhi insomnia. (tabel 3)

\section{PEMBAHASAN}

Berdasarkan studi oleh Gambhir (2014) mengenai insomnia pada geriatri yang berbasis pada penelitian rumah sakit, menemukan angka kejadian insomnia yag tertinggi yaitu pada kelompok usia 60-69 tahun yaitu dengan proporsi $20 \%{ }^{8}$ Temuan tersebut merupakan temuan serupa dengan yang didapatkan oleh peneliti. Kejadian insomnia pada geriatri dipengaruhi oleh faktor usia yang menyebabkan semakin tingginya kejadian insomnia seiring dengan bertambahnya usia, keadaan ini diduga akibat adanya suatu penurunan pada dorongan homeostatis tidur pada geriatri. ${ }^{9}$

Studi lain oleh Itani (2016) mengenai epidemiologi insomnia di Jepang menemukan bahwa, jenis kelamin perempuancenderunglebihbanyakdibandingkan dengan laki-laki yaitu dengan proporsi $57 \% .{ }^{10}$ Jenis kelamin perempuan merupakan faktor resiko mayor untuk insomnia. Perbedaan kejadian berdasarkan jenis kelamin dimulai pada saat terjadinya onset menstruasi, hal tersebut memberi kesan bahwa perubahan hormonal dari sex steroid dan sesitivitas neuro-endokrin yang terjadi pada masa pubertas dapat secara langsung maupun tak langsung mempengaruhi fenomena ini. ${ }^{11}$

Berdasarkan hasil penelitian status pernikahan janda/duda cenderung lebih banyak dibandingkan dengan status menikah yaitu dengan proporsi $68.8 \%$. Studi lain oleh Shahar (2011) mengenai depresi dan insomnia pada geriatri di Negara Malaysia, menemukan bahwa karakteristik subjek yang dengan sttus janda/duda lebih banyak dibandingkan dengan proporsi $67.3 \% .{ }^{12}$ Keadaan ini kemungkinan dipengaruhi oleh suatu keadaan usia yang tua sehingga terdapat suatu kecendrungan bahwa pasangan hidup yang telah meninggal karena usia tua yang menyebabkan status perkawinan janda/ duda. Keadaan janda/duda menyebabkan suatu stressor yang besar bagi individu, dimana hal tersebut menimbulkan suatu pemikiran akan kesendirian yang akan dihadapi, kemudian pemikiran akan suatu keputusasaan akan menjalani hidup seorang diri yang cenderung dapat bermanifestasi dalam berbagai gangguan seperti gangguan tidur. ${ }^{11}$

Berdasarkan penelitian ini prevalensi dari insomnia adalah 50\%. Studi lain oleh Shahar (2011) mengenai depresi dan insomnia pada geriatri di Negara Malaysia, menemukan bahwa prevalensi depresi pada penelitian tersebut adalah $52 \%$, temuan tersebut merupakan temuan prevalensi yang sedikit lebih tinggi dibandingkan dengan penelitian ini. ${ }^{12}$ Studi lain oleh Wang (2017) mengenai Depresi pda geriatri, yang melibatkan 276 subjek penelitian geriatri. Menemukan bahwa prevalensi depresi pada kalangan geriatri sebesar $31 \%{ }^{13}$

Berbagai prevalensi depresi yang ada pada penelitian tersebut tentunya dipengaruhi oleh berbagai hal seperti karakteristik individu yang berbeda serta kondisi lingkungan yang berbeda, keadan ini cenderung menjadi penyebab gambaran depresi yang berbeda-beda pada penelitian tersebut.

Hasil penelitian ditemukan nilai odd ratio 5,44, $p=0,049(p<0,05)$ sehingga dapat disimpulkan bahwa terdapat hubungan yang bermakna antara depresi dan insomnia dan depresi merupakan faktor resiko untuk insomnia. Studi lain oleh Sharar (2011) mengenai determinan depresi dan insomnia pada 71 geriatri di Negara Malaysia, menemukan terdapat adanya hubungan antara depresi dan insomnia $(p<0,001){ }^{12}$ Teuan tersebut merupakan temuan yang serupa dengan yang didapatkan oleh peneliti. Keadaan depresi memang sering ditemukan pada kelompok yang mengalami insomnia, namun hubungan sebab akibat antara kedua hal tersebut masih belum dimengerti secara penuh. 
Depresi sering muncul pada pasien dengan insomnia dan tingkat keparahan dari depresi berjalan seiring dengan tingkat keparahan dari insomnia, selain itu kelompok geriatri yang mengalami insomnia, memiliki resiko 3-7 kali lebih besar untuk mengalami depresi dibandingkan dengan kelompok geriatri yang tidak mengalami insomnia. ${ }^{14}$

\section{SIMPULAN}

Prevalensi depresi pada geriatri dalam penelitian ini adalah $28,1 \%$, sedangkan prevalensi insomnia pada penelitian ini adalah $50 \%$, depresi merupakan faktor resiko dari terjadinya insomnia pada geriatri.

\section{DAFTAR PUSTAKA}

1. Luo J. Prevalence and risk factors of poor sleep quality among chinese elderly in an urban community: Results from the Shanghai aging study,PLoS ONE. 2013;8(11):1-7.

2. Sadock BJ, Kaplan HI. Kaplan \& Sadock's Pocket Handbook of Clinical Psychiatry. Eleventh edition. 2015. New York: Mc-Graw-Hill.

3. Chen Y. Association between chronic insomnia and depression in elderly adults. Journal of the Chinese Medical Association. 2012;75(5):195-199.

4. Drake CL, Pillai V, Roth T. Stress and sleep reactivity: a prospective investigation of the stress-diathesis model of insomnia. Sleep. 2014;37(8):1295-1304.

5. Marasinghe C. Sleep disorders in elderly, Journal of the Ceylon College of Physicians. 2012;43(1):37-40.
6. Suh S. Longitudinal course of depression scores with and without insomnia in non-depressed individuals: a 6-year follow-up longitudinal study in a Korean cohort. Sleep. 2013;36(3):369-376

7. Jaussent I. Insomnia and daytime sleepiness are risk factors for depressive symptoms in the elderly. Sleep. 2011;34(8):1103-1110.

8. Gambhir IS. Journal of Clinical Gerontology \& Geriatrics Insomnia in the elderly d A hospital-based study from North India, Journal of Clinical Gerontology \& Geriatics. 2014;5(4):117-121.

9. Tsou MT. Prevalence and risk factors for insomnia in community-dwelling elderly in northern Taiwan. Journal of Clinical Gerontology and Geriatrics. 2013;4(3):75-79.

10. Itani O. Nationwide epidemiological study of insomnia in Japan. Sleep Medicine. 2016;12(3):118-124

11. Zambotti M. Insomnia disorder in adolescence: diagnosis, impact, and treatment. Sleep Medicine Reviews. 2017;10(2):130-135.

12. Shahar S. Determinants of depression and insomnia among institutionalized elderly people in Malaysia. Asian Journal of Psychiatry. 20114;4(3):188- 195.

13. Wang K. Depression in Older Adults Among Community: The Role of Executive Function. International Journal of Gerontology. 2017;1(2):4-8.

14. Chen Y. Association between chronic insomnia and depression in elderly adults,. Journal of the Chinese Medical Association. 2012;75(5):195-199.

15. Dehghanmenhr S, Shadadi H, Mansouri A, Arbabisarjou A. Effect of oral saffron capsules on sleep quality in patients with diabetes at Zabol-Iran. Bali Med J. 2017;6(3):595-600.

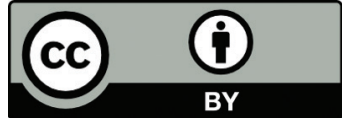

This work is licensed under a Creative Commons Attribution 